تأثير الإصابة بفيروس موزييك الخيار (Cucumber mosaic virus) في محتوى البرولين وبيروكسيد الهيدرجين

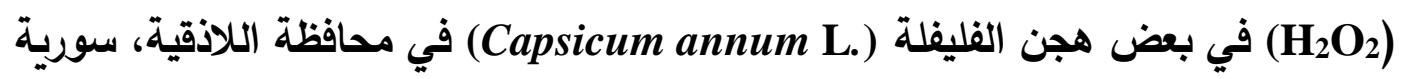

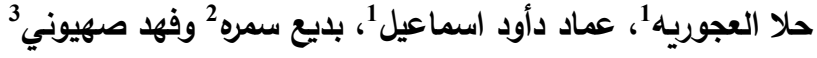

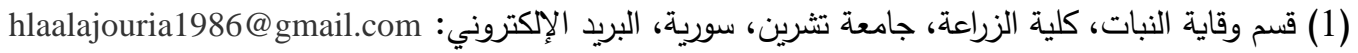

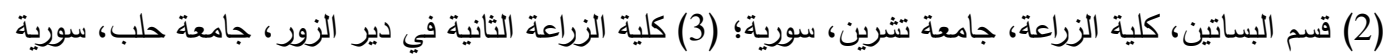

\title{
الملخص
}

العجوريه، حلا، عماد دأود اسماعيل، بديع سمره وفها صهيوني. 2021. تأثير الإصابة بفيروس موزييك الخيار (Cucumber mosaic virus)

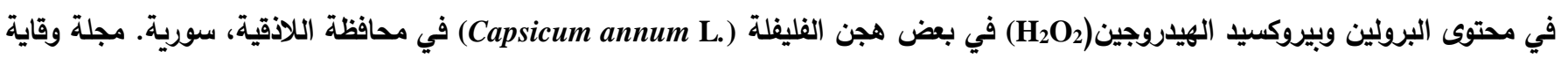
النبات العربية، 39 (1): 39-46-

أجريت التجربة الحقلية في قرية المتركية في محافظة اللاذقية، خلال الموسم الزراعي 2020/2019، بهدف معرفة تأثير الإصابة بفيروس موزاييك الخيار (CMV) Cucumber mosaic virus

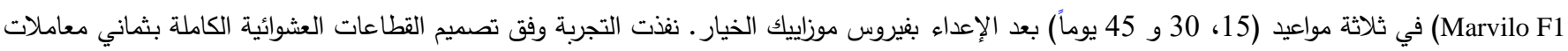

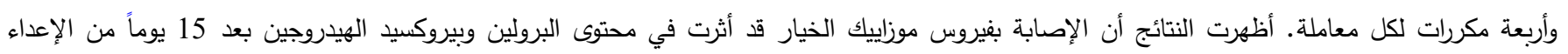

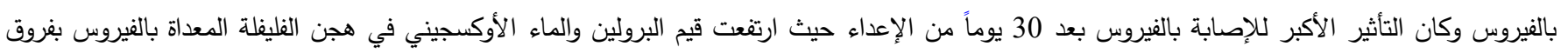

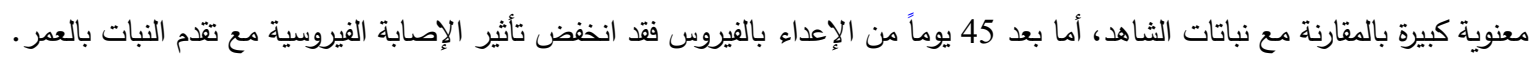

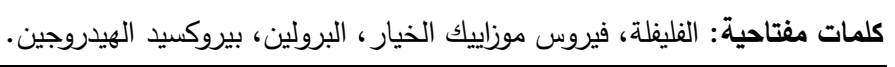

الظروف البيئية الملائمة لانتشارها، لذلك كانت الوقاية من الفيروسات المقدمة

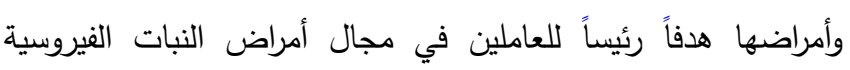

$$
\text { (الحمادي وآخرون، 2008). }
$$

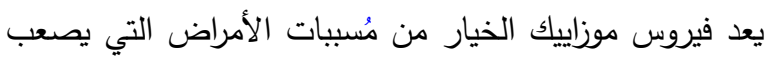

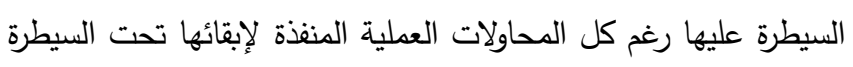

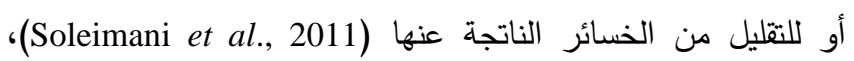
خاصة من خلال مكافحة نواقل الفيروس الحشرية (المنّ) بالمبيدات

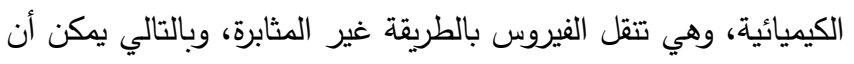

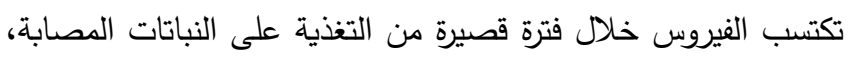

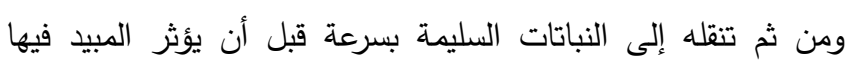

.(Zehnder et al., 2001)

أشارت العديد من الدراسات إلى زيادة معنوية في محتوى (Zeh

Pazarlar Berber \& Önlü, 2012) البرولين تحت الإجهادات البيئية (et al., 2013 كما وتزيد العدوى الفيروسية من نشاط البيروكسيداز

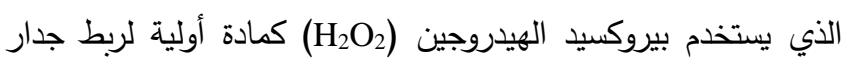
الخلية فترتفع بذلك قساوته وكثافته (Montalbini et al., 1995). تعد الفليفلة من محاصيل الخضار في الزراعة الحقلية في القطر العربي السوري ذات القيمة الغذائية العالية، ولها استخدامات طبية وغذائية لزئية عديدة، وتُستخدم في إنتاج الزيوت العطرية والصبغات الملونة

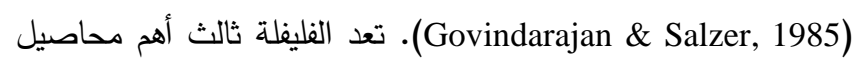

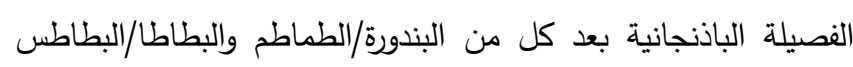

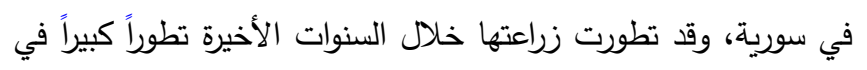
بلدان حوض البحر المتوسط، ومنها سورية حيث بلغت المساحة المزروعة من الفليفلة لعام 2017 على مستوى القطر العربي السوري

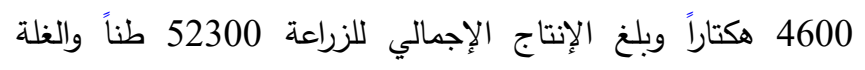

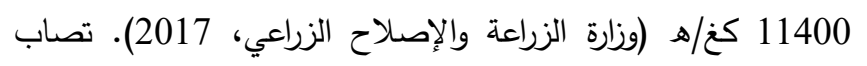

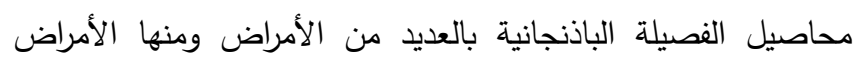

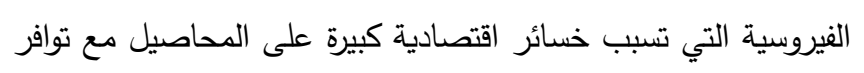


تمت عمليات تحضير التربة للزراعة بحراثة خريفية أساسية

أضيفت معها الأسمدة العضوية بمعدل 3 كغ/م² وإضافة الأسمدة المعدنية بطيئة التحلل (سوبر فوسفات وسلفات البوتاسيوم بمعدل 50 غار2² و60 غ/م²، على التوالي). تم تحريك التربة قبل الزراعة بحراثة سطحية بوساطة الكالتيفاتور مع إضافة جزء من السماد الآزوتي

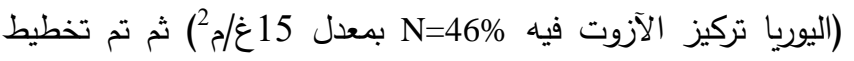
الأرض للزراعة بخطوط بعرض 60 سم وأبعاد الزراعة بين النباتات 40 سم في الخط الواحد وترك فاصل بين المكررات 60 سم لمنع تلامس النباتات بين المعاملات المختلفة. كما تركت أيضاً مسافة فاصلة بين نباتات كل هجين 140 سم، وزرع نطاق حماية من الفليفلة حول نباتات التجربة بطول 4 م (15 نبات من كل جهة).

تصميم التجربة

تمت زراعة نباتات التجربة وفق تصميم القطاعات العشوائية الكاملة حيث شملت التجربة 8 معاملات (معاملتان لكل هجين) وبأربعة مكررات لكل معاملة ويتكون المكرر من 8 نباتات وكانت معاملات

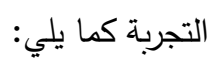

Taline F1 المعاملة الأولى: نباتات فليفلة من الهجين الحريف -

بدون إعداء بالفيروس (شاهد للهجين الحريف Taline F1). Amani F1 المعاملة الثانية: نباتات فليفلة من هجين غير الحريف ل- ل بدون إعداء بالفيروس (شاهد للهجين غير الحريف Amani F1).

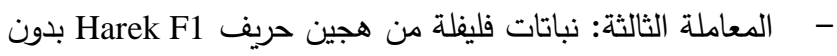

إعداء بالفيروس (شاهد للهجين الحريف Harek F1).

Marvilo F1 المعاملة الرابعة: نباتات فليفلة من هجين غير حريفئن -

بدون إعداء بالغيروس (شاهد للهجين غير الحريف Marvilo F1).

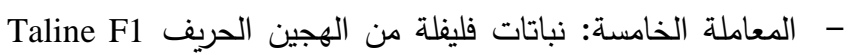
مع إعداء بالفيروس.

Amani المعاملة السادسة: نباتات فليفلة من هجين غير الحريف: F1

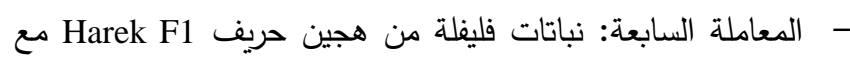
إعداء بالفيروس.

Marvilo F1 المعاملة الثامنة: نباتات فليفلة من هجين غير حريف برون -

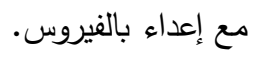

\section{عمليات الخدمة}

قدمت لنباتات التجربة عمليات الخدمة الزراعية اللازمة من ري وعزيق كميق وتعشيب وإضافة الجزء المتبقي من الأسمدة الآزوتية كتسميد إضافي مع ماء الري السطحي على دفعتين بمعدل 15غ/2² بعد العزيق الأول،
هدف هذا البحث إلى دراسة تأثير العدوى بفيروس موزاييك

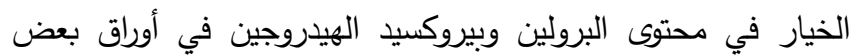
هجن الفليفلة المصابة بالفيروس.

\section{مواد البحث وطرائقه}

المادة النباتية

استخدمت بذور أربعة هجن من الفليفلة هي: 1- الهجين Taline F1 وهو من هجن الفليفة الحريفة يتميز بنمو خضري غزير، أوراقه صغيرة نسبياً، ثماره عبارة عن قرون رفيعة متطاولة، من إنتاج شركة ميرو سيدز -هولندا، يتميز بنسبة إنبات \% 75 ونقاوة 98\%، وبذوره معقمة بالثيرام.

2- الهجين Amani F1 وهو هن هجن الفليفلة غير الحريفة يتميز بنمو خضري غزير، أوراقه عريضة نسبياً، ثماره كبيرة عربضة، منة المنشأ هولندا، يتميز بنسبة إنبات 93\% ونقاوة 98\%، وبذوبة وبذوره معقدة بالثيرام الهجين Harek F1 وهو من هجن الفليفلة الحريفة يتميز بنمو خضري غزير، أوراقه صغيرة نسبياً، ثماره عبارة عن هن قرون رفيعة متطاولة، من إنتاج شركة سيمنس فيجيتبل سيدس-

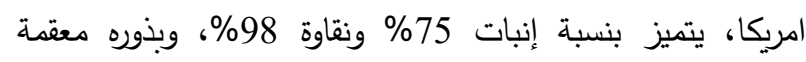
بالثيرام. 3- الهجين Marvilo F1 وهو من هجن الفليفلة غير الحريفة يتميز بنمو خضري غزير ، أوراقه عريضة نسبياً، ثماره كبيرة عريضة، من فن فين

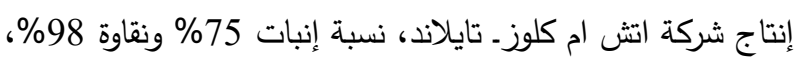
وبذوره معقدة بالثيرام

مكان وزمان تنفيذ البحث نفذ البحث في الموسم الزراعي 2020/2019 في قرية المتركية الواقعة في السهل الساحلي الجنوبي لمحافظة اللاذقية على بعد 15 كم جنوب

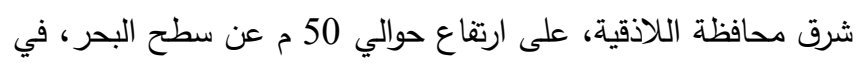
حقل مفتوح مساحته 1000 م وتربته رملية طينية.

إنتاج الثتول وإعداد الأرض للزراعة زرعت بذور هجن الفليفلة الأربعة في صواني فلينية مملوءة بالتورب الزراعي. غطيت صواني الإنبات بالثباك الناعمة لمنع دخول الحشرات. وبعد الإنبات قدمت للبادرات عمليات الخدمة الزراعية اللازمة. وبعد حوالي ثلاثة أسابيع نقلت البادرات إلى أكياس زراعية من البولي ايتيلين لونها أسود أبعادها 10×10 سم وعندما وصلت الشتول لمرحلة الورقة الحقيقية الرابعة والخامسة تم نقلها إلى الأرض الدائمة. 
سحق 100 مغ من الأوراق النباتية الطازجة من جميع مكررات

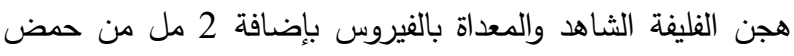

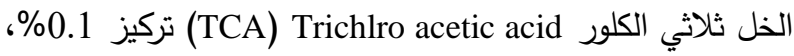
ثم وضعت العينات في جهاز الطرد المركزي على سرعة 12000

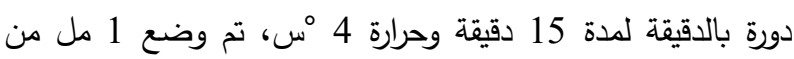
الرشاحة السائلة لكل أنبوب في أنابيب زجاجية مع 0.5 مل من دورة محلول منظم فوسفات البوتاسيوم المتعادل ( $)$

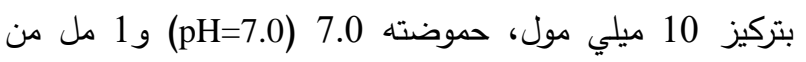
يوديد البوتاسيوم النظامي (KI). تم تحضير عينات الشاهد بإضافة

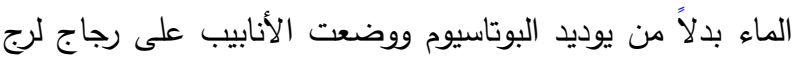

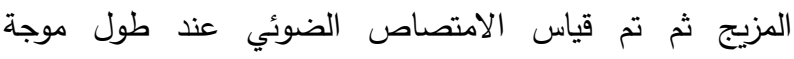

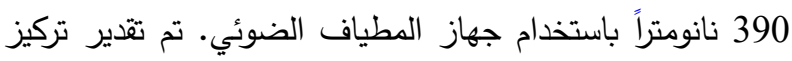

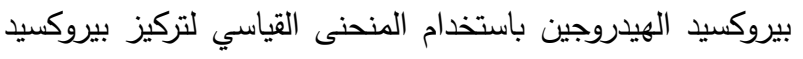
الهيدروجين.

\section{التحليل الإحصائي}

R statistical مع إجراء تحليل التباين للبيانات باستخدام البرنامج

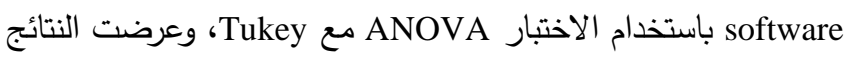
بشكل متوسطات مضافاً لها الخطأ المعياري (means

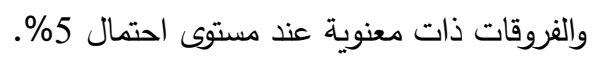

\section{النتائج والمناقشة}

إنتاج البرولين

لوحظ بعد 15 يوماً من إعداء نباتات الفليفلة بفيروس موزاييك الخيار

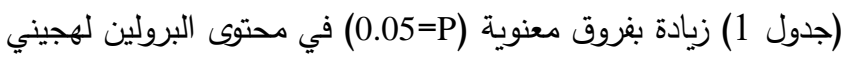
الفليفلة Harek F1 TlineF1 (3.19 و 2.56 ميكروغرام/غرام، على مئى التوالي) وذلك بالمقارنة مع نباتات الشاهد لكل منهما (2.54 و 2.00 و 2.56 ميكروغرام/غرام، على التوالي) ولم يلاحظ وجود فرق معنوي (0.05=Pاتل

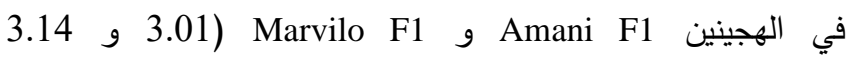
ميكروغرام/غرام، على التوالي) بالمقارنة مع نباتات الشاهد لكل منهما

$$
\text { (2.83 و } 3.03 \text { ميكروغرام/غرام، على التوالي). }
$$

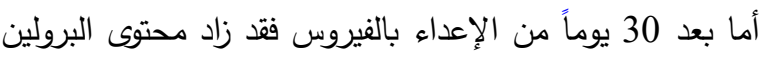

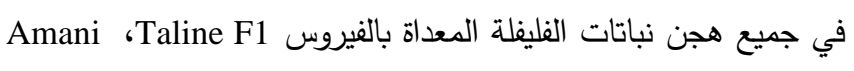
Harek F1 F1 ميكروغرام/غرام، على التوالي) بفروق معنوية كبيرة (0.05=P) بالمقارنة

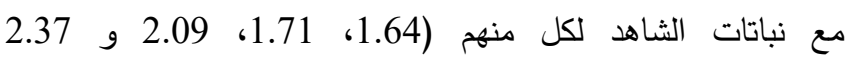
ميكروغرام/غرام، على التوالي) (جدول 1).
بعد شهر من إضافة الدفعة الإضافية الأولى. كما تمت حماية النباتات من الآفات المختلفة بالرش الوقائي بالمبيدات المنافية الألى الإبة للوقاية من الأمراض الفطرية وبخاصة البياض الزغبي والبياض الدقيقي واللفحة

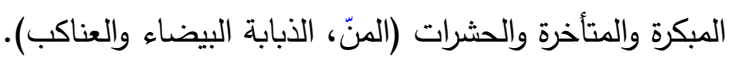

\section{العزلة الفيروسية المستخدمة في الدراسة وإجراء العدوى}

Cucumber استخدمت في هذه الدراسة عزلة لفيروس موزييك الخيار جنس CMV) mosaic virus (Bromoviridae

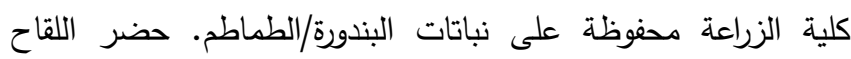

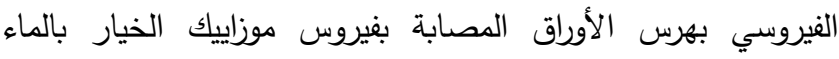

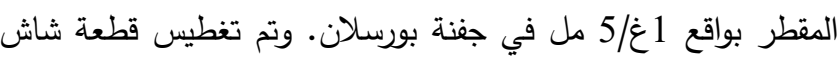

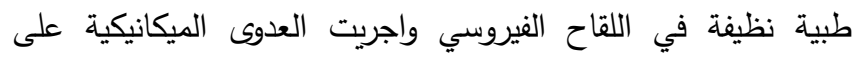
الأوراق العلوية للنباتات بعد 20 يوماً من زراعتها في الأرض الدائمة

$$
\text { بعد تعفيرها بمادة مخرشه (كربيد السيليكون). }
$$

القراءات المأخوذة

تمت الدراسة على 64 نباتاً من كل هجين (32 شاهد، 32 معدى المدرد بالفيروس) وتم حساب كل من البرولين وبيروكسيد الهيدروجين كما

- البرولين: تم تحليل محتوى الأوراق من البرولين وفقاً لدراسة سابقة

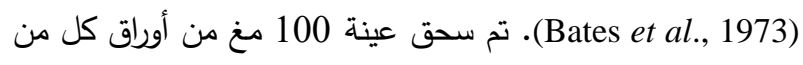

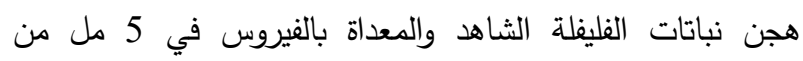

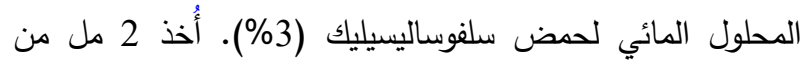

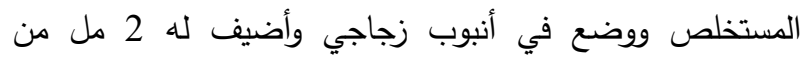

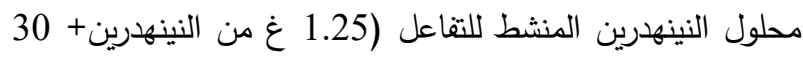

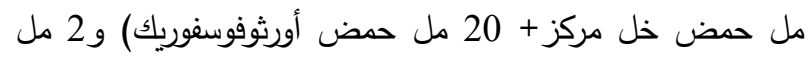
من حض الخل الثلجي، وتم المزج مع الرج جيداً على رجاج

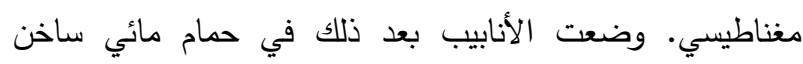

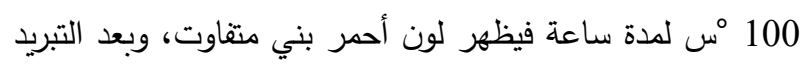

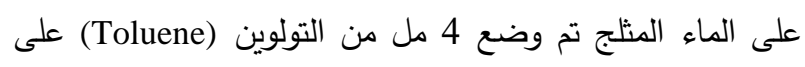
كل عينة ثم رجت جيداً بواسطة محرك دائري (Vortex mixer). تم قياس الامتصاص الضوئي على طول موجة 520 نانومتر

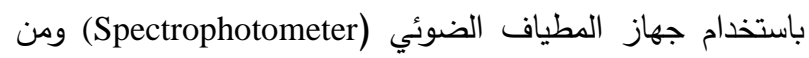
ثم تقدير نسبة البرولين في العينات بالاعتماد على منحى قياسي للبرولين النقي. - بيروكسيد الهيدروجين: تم تحليل محتوى الأوراق من بيروكسيد

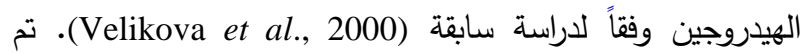


بالفيروس زيادة محتوى البرولين في جميع المعاملات بالمقارنة مع الثاهد. أفاد (Palfi \& Juhasz 1969) بأن تعرض الأنسجة النياد النباتية للإجهاد يؤدي إلى سرعة تمثيل البرولين وتثبط أكسدته ثم تراكمه داخل نعرض الإنه الأنسجة، وقد أشار Stewart (1983) أن تجمع البرولين يعتبر بمثابة

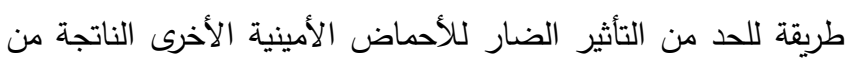

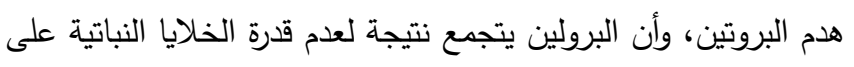

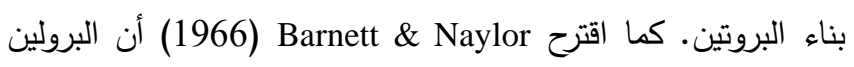

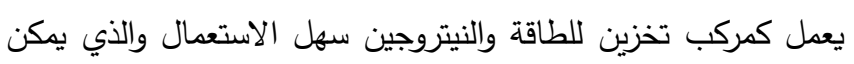

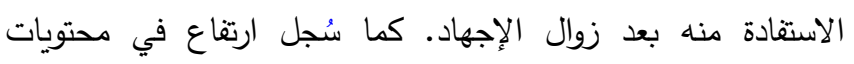

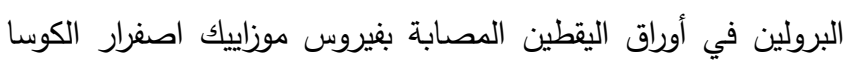
بالمقارنة مع نباتات الثاهد (Zucchini yellow mosaic virus)

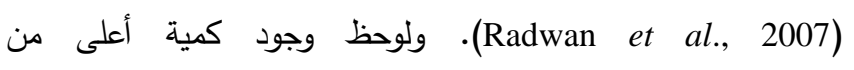
محتويات البرولين في أوراق هجن متتوعة من نباتات الفليفلة 497 F1 ،Kumsal F1 6Evgenekon F1 (Capsicum annum L.) المصابة بفيروس موزاييك التبغ (Tobacco mosaic virus) بالمقارنة (Cيراتي

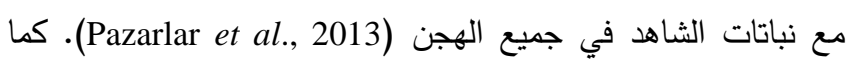

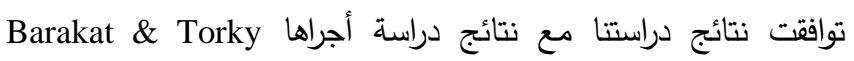

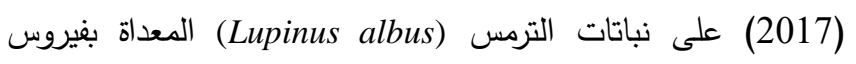
موزاييك اصفرار الفاصولياء (Bean yellow mosaic virus) بعد 1) 2 و 3 أسابيع من الإعداء حيث كان محتوى البرولين أعلى بكثير في

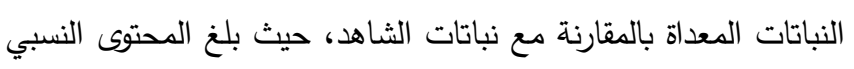

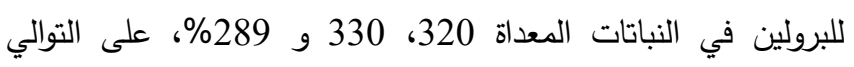

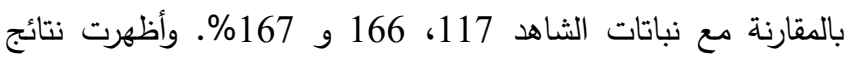
دراسة سابقة (Shahrukh et al., 2014) على نباتات الموز المصابة

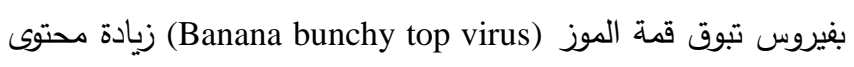

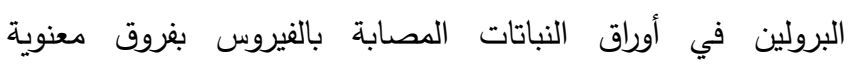
بالمقارنة مع نباتات الثاهد.

\section{إنتاج بيروكسيد الهيدروجين (H2)} لوحظ بعد 15 يوماً من إعداء نباتات الفليفلة بفيروس موزاييك الخيار

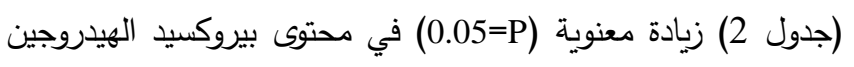

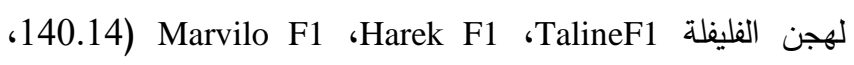

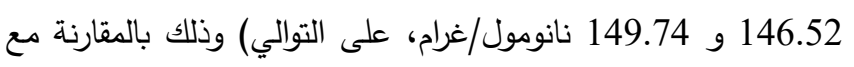

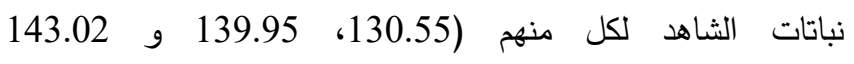

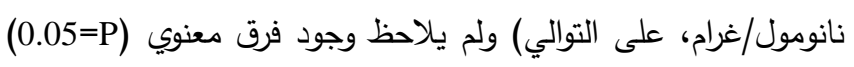

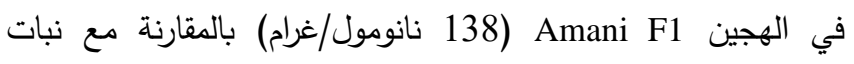
الشاهد (136.53 نانومول/غرام).
وبعد 45 يوماً من الإعداء بالفيروس لوحظ انخفاض في تأثير

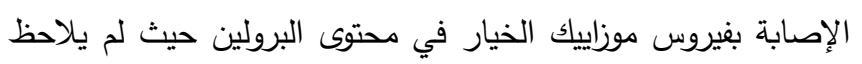

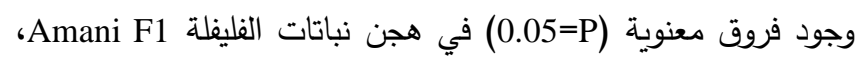
Harek F1

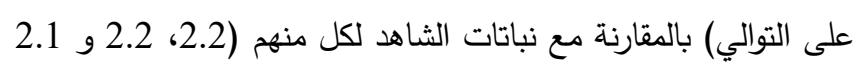

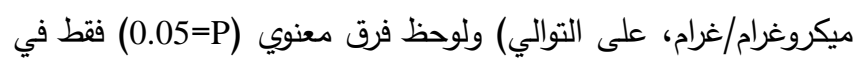

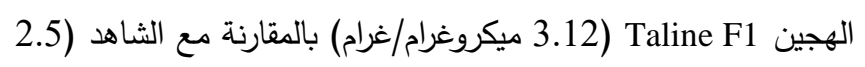
ميكروغرام/غرام) (جدول 1). مما سبق نستتتج أن تأثير العدوى بفيروس موزاييك الخيار في محتوى البرولين كان واضحاً بعد 15 يوماً من الإعداء بالفيروس ولكن نئن فئن كان التأثير الأكبر للفيروس بعد 30 يوماً من العدوى، أما بعد 45 يوماً

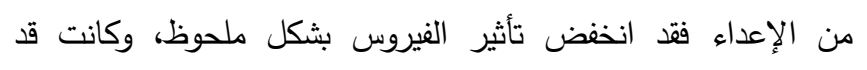

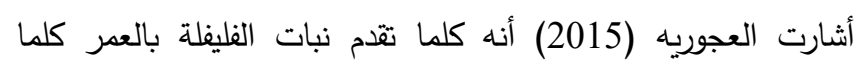
انخفض تأثير الإصابة بفيروس موزييك الخيار فيه.

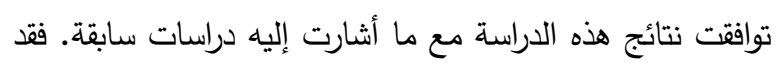
سُجل ارتفاع ملحوظ في محتويات البرولين في أوراق سلالات الفليفلة

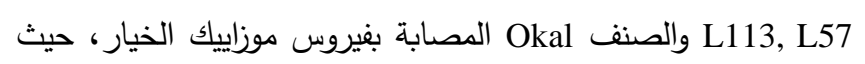
كانت محتويات البرولين مرتفعة بشكل ملحوظ في أوراق الصنف Okal

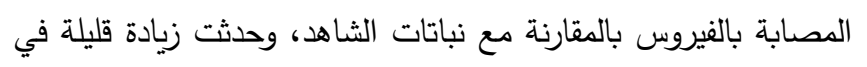

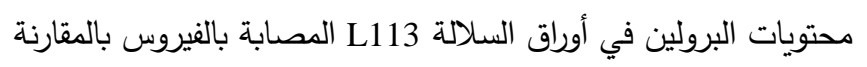

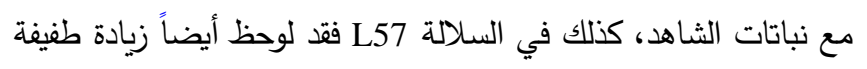
في محتوى البرولين في الأوراق المصابة بالمقارنة مع نباتات الثاهد.

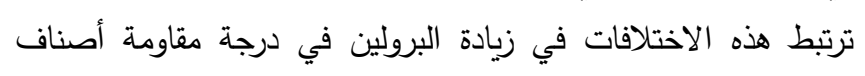

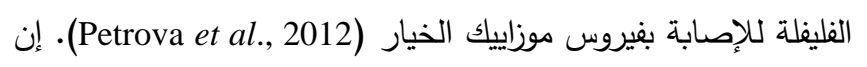
تراكم البرولين هو الزيادة في مستوى البرولين الحر في النسيج ويعزى الني

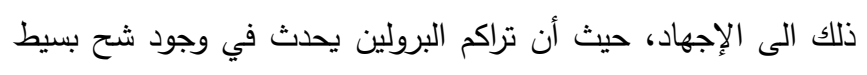

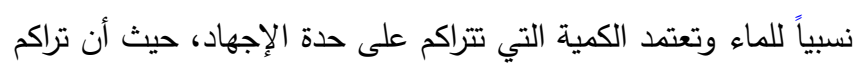

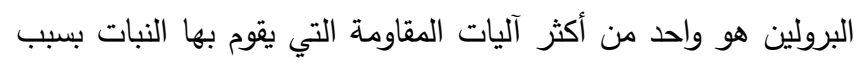

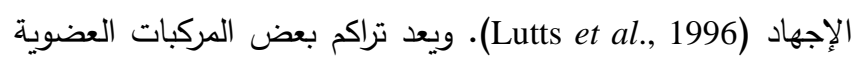

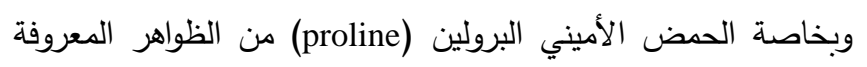

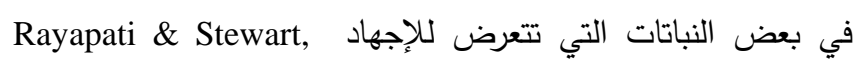

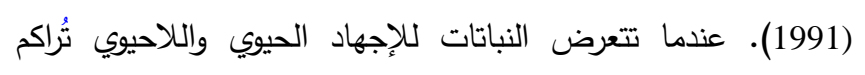

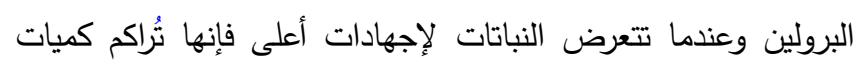

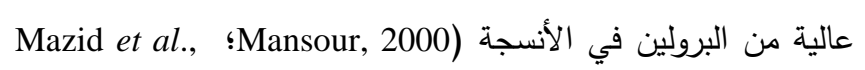
2011). وأظهرت نتائج دراسة أخرى (Gholi-Tolouie et al., 2018) تم فيها تقويم التغيرات في إنتاج البرولين في نباتات البندورة/الطماطم المصابة بفيروس (Solanum lycopersicum cv. Superchief) موزاييك الخيار بعد 0، 1، 2، 4، 6، 8 و 15 يوماً من الإعداء 
جدول 1. تأثير الإصابة بفيروس موز اييك الخيار في محتوى البرولين (ميكروغر ام/غر ام) في أوراق هجن الفليفلة. Table 1. The effect of Cucumber mosaic virus infection on proline content (micro g/g) in pepper hybrid leaves.

\begin{tabular}{|c|c|c|c|}
\hline \multicolumn{3}{|c|}{ Proline content (microgram/g leaves) محتوى البرولين (ميكروغرام/غرام أوراق) } & \multirow[b]{2}{*}{$\begin{array}{r}\text { المعاملات (هجن القليقلة) } \\
\text { Treatments (Pepper hybrids) }\end{array}$} \\
\hline $\begin{array}{l}\text { بعد } 45 \text { يوماً من الإعداء } \\
45 \text { days post virus } \\
\text { inoculation }\end{array}$ & $\begin{array}{l}\text { بعد } 30 \text { يوماً من الإعداء } \\
30 \text { days post virus } \\
\text { inoculation }\end{array}$ & $\begin{array}{l}\text { بعد } 15 \text { يوماً من الإعداء } \\
15 \text { days post virus } \\
\text { inoculation }\end{array}$ & \\
\hline $2.50 \pm 0.267 \mathrm{~b}$ & $1.64 \pm 0.029 \mathrm{~d}$ & $2.54 \pm 0.031 \mathrm{~b}$ & Control (شاهد) Taline F1 \\
\hline $2.20 \pm 0.184 \mathrm{~b}$ & $1.71 \pm 0.020 \mathrm{c}$ & $2.83 \pm 0.174 \mathrm{ab}$ & Control (شاهد) Amani F1 \\
\hline $2.20 \pm 0.207 \mathrm{~b}$ & $2.09 \pm 0.186 \mathrm{~b}$ & $2.00 \pm 0.221 \mathrm{~d}$ & Control (شاهد) Harek F1 \\
\hline $2.10 \pm 0.251 \mathrm{~b}$ & $2.37 \pm 0.139 \mathrm{~b}$ & $3.03 \pm 0.119 \mathrm{a}$ & Control (شاهد) Marvilo F1 \\
\hline $3.12 \pm 0.098 \mathrm{a}$ & $2.80 \pm 0.418 \mathrm{a}$ & $3.19 \pm 0.170 \mathrm{a}$ & Taline F1+CMV \\
\hline $2.32 \pm 0.097 \mathrm{~b}$ & $2.31 \pm 0.346 \mathrm{ab}$ & $3.01 \pm 0.237 \mathrm{a}$ & Amani F1+CMV \\
\hline $2.47 \pm 0.134 \mathrm{~b}$ & $3.00 \pm 0.320 \mathrm{a}$ & $2.56 \pm 0.128 \mathrm{c}$ & Harek F1+CMV \\
\hline $2.27 \pm 0.087 \mathrm{~b}$ & $3.00 \pm 0.272 \mathrm{a}$ & $3.14 \pm 0.287 \mathrm{a}$ & Marvilo F1 + CMV \\
\hline
\end{tabular}

Means followed by the same letters in the same column are not significantly different at $\mathrm{P}=0.05$.

جدول 2. تأثير الإصابة بفيروس موز اييك الخيار في محتوى بيروكسيد الهيدروجين (نانومول/غرام) لأوراق هجن نباتات الفليفلة. Table 2. The effect of Cucumber mosaic virus infection on hydrogen peroxide content (nanomol/g) in pepper hybrid leaves.

\begin{tabular}{|c|c|c|c|}
\hline \multicolumn{3}{|c|}{ بيروكسيد الهيدروجين نانومول/غرام Hydrogen peroxide (nanomol/g) } & \multirow[b]{2}{*}{$\begin{array}{r}\text { المعاملات (هجن القليقلة) } \\
\text { Treatments (Pepper hybrids) }\end{array}$} \\
\hline $\begin{array}{l}\text { بعد } 45 \text { يوماً من الإعداء } \\
45 \text { days post virus } \\
\text { inoculation }\end{array}$ & $\begin{array}{c}\text { بعد } 30 \text { يوماً من الإعداء } \\
30 \text { days post virus } \\
\text { inoculation }\end{array}$ & $\begin{array}{c}\text { بعد } 15 \text { يوماً من الإعداء } \\
15 \text { days post virus } \\
\text { inoculation }\end{array}$ & \\
\hline $122.25 \pm 6.72 \mathrm{a}$ & $166.32 \pm 2.10 \mathrm{c}$ & $130.55 \pm 3.22 \mathrm{c}$ & Control (شاهد) Taline F1 \\
\hline $113.14 \pm 0.75 \mathrm{~b}$ & $173.70 \pm 1.98 \mathrm{~b}$ & $136.53 \pm 2.98 \mathrm{~b}$ & Control (شاهد) Amani F1 \\
\hline $129.50 \pm 6.61 \mathrm{a}$ & $166.32 \pm 1.14 \mathrm{c}$ & $139.95 \pm 2.82 \mathrm{~b}$ & Control (شَاهد) Harek F1 \\
\hline $112.30 \pm 3.12 \mathrm{~b}$ & $172.71 \pm 2.12 \mathrm{~b}$ & $143.02 \pm 2.23 \mathrm{~b}$ & Control(شاهد) Marvilo F1 \\
\hline $126.80 \pm 3.82 \mathrm{a}$ & $173.15 \pm 1.75 \mathrm{~b}$ & $140.14 \pm 2.14 \mathrm{~b}$ & Taline F1+CMV \\
\hline $114.40 \pm 3.19 \mathrm{~b}$ & $179.95 \pm 1.55 \mathrm{a}$ & $138.00 \pm 1.28 \mathrm{~b}$ & Amani F1+CMV \\
\hline $131.70 \pm 3.08 \mathrm{a}$ & $174.39 \pm 1.00 \mathrm{~b}$ & $146.52 \pm 2.11 \mathrm{a}$ & Harek F1+CMV \\
\hline $116.60 \pm 2.98 \mathrm{~b}$ & $184.00 \pm 2.59 \mathrm{a}$ & $149.74 \pm 3.11 \mathrm{a}$ & Marvilo F1 + CMV \\
\hline
\end{tabular}

Means followed by the same letters in the same column are not significantly different at $\mathrm{P}=0.05$.

وبعد 45 يوماً من الإعداء بالفيروس لوحظ انخفاض في تأثير

الإصابة بفيروس موزاييك الخيار في محتوى بيروكسيد الهيدروجين

حيث زاد محتوى بيروكسيد الهيدروجين زيادة غير معنوية (0.05=P)

في جميع هجن نباتات الفليفلة المعاملة بالفيروس Taniline F1، 131.7 114.4 3arek F1 ،F1 و 116.6 نانومول/غرام، على التوالي) بالمقارنة مع نباتات الشاهد لكل

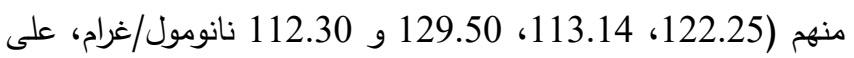

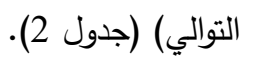

أما بعد 30 يوماً من الإعداء بالفيروس فقد زاد محتوى بيروكسيد

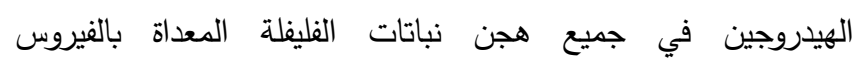
،173.15) Marvilo F1 ،Harek F1 ،Amani F1 ،Taline F1 179.95، 174.39 و 184.00 نانومول/غرام، على التوالي) بفروق معنوية كبيرة (0.05=P) بالمقارنة مع نباتات الشاهد لكل منهم

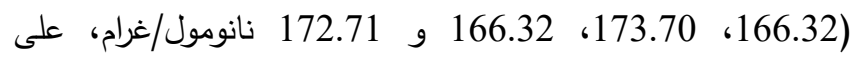

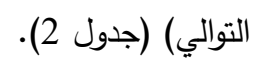


الثاهد (Kiraly et al., 2008). وأظهرت نتائج دراسة أخرى زيادة مستوى بيروكسيد الهيدروجين في أوراق (Kiraly et al., 2002) نباتات التبغ عند إصابتها بفيروس موزاييك التبخ وذلك بسبب حدوث تماوت/نخر في أنسجة الأوراق المصابة بالمقارنة مع نباتات الثاهد. كما وسجلت تركيزات عالية من بيروكسيد الهيدروجين لوحظت في أوراق نباتات التبخ المعداة بفيروس موزاييك التبخ ( Doke \& Ohashi, 1988). وفي دراسة أخرى (Xi et al., 2007) أجريت لمعرفة تأثير الإصابة المشتركة بين فيروس موزاييك الخيار وفيروس النكرزة في التبغ Nicotiana في نبات التبغ (Tobacco necrosis virus) benthamiana في مستويات الميلونيل ديالديهيد وبيروكسيد الهيدروجين وانخفاض أكبر في نشاط الكاتالاز بالمقارنة مع الإصابة المفردة. كما توافقت نتائج

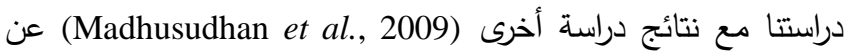
تأثير الإصابة بفيروس موزاييك التبخ وفيروس موزاييك البندورة/الطماطم في التغيرات في الأنزيمات المضادة (Tomato mosaic virus) للأكسدة في نباتات البندورة/الطماطم والفليفلة الحلوة ونباتات التبغ حيث (Nicotiana glutinosa \& Nicotiana tabacum cv. Xanthi) لوحظ زيادة في بيروكسيد الهيدروجين في جميع النباتات المدروسة نتيجة الإصابة الفيروسية. كما وسجل تراكم بيروكسيد الهيدروجين في نبات Arabidopsis thaliana المعداة بفيروس موزاييك القرنبيط (Cove et al., 2005) (Cauliflower mosaic virus) نشاط الكاتالاز نتيجة إصابة نباتات التبغ بفيروس موزاييك التبغ وهذا

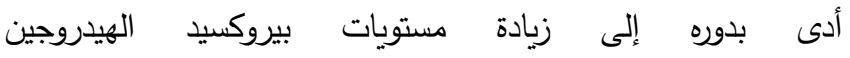
.(Neuenschwander et al., 1995)
مما سبق نستتتج أن تأثير الإعداء بفيروس موزاييك الخيار في محتوى بيروكسيد الهيدروجين كان واضحاً بعد 15 يوماً من الإعداء

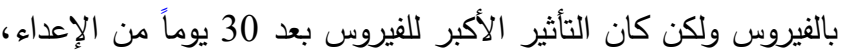
أما بعد 45 يوماً من الإعداء فقد انخفض تأثير الفيروس بشكل ملحوظ، بأني وهذا يتوافق مع ما نشر سابقاً (العجوريه، 2015) إلى أنه كلما تقدم نبات الفليفلة بالعمر كلما انخفض تأثير الإصابة بفيروس موزاييك الخيار عليه.

توافقت نتائج هذه الدراسة مع ما أشارت إليه دراسات سابقة. فقد زادت الإصابة الفيروسية عند دراسة الإجهادات التأكسدية في تفاعلات النبات مع الفيروس في نباتات الخيار (Cucumis sativus) ونباتات الكوسا (Cucurbita pepo) المصابة بفيروس موزاييك الخيار وفيروس موزاييك اصفرار الكوسا من أكسدة الحموض الدهنية غير المشبعة مؤدياً ذلك إلى ضرر الأغشية الخلوية. تعمل الجذور الحرة المتشكلة خلال أكسدة الدهون على أكسدة جزيئات الصبغات وهذ يفسر ظهور أعراض الاصفرار على النباتات المصابة، كذلك فئن أنزيمات البيروكسيداز إضافة إلى وظيفتها في كنس الجذور الحرة فإنها تحفز تشكيل بيروكسيد الهيدروجين وهذا يساهم في الإجهاد التأكسدي في التفاعلات الجهازية للفيروسات النباتية، كذلك فإن الاكسدة المرتفعة لأنزيمات البيروكسيداز لهرمون إندول حمض الخل يكون مسؤولاً أيضاً عن انخفاض النمو والتشوهات في النباتات المصابة بالفيروس (Riedle-Bauer, 2000). كما سجل ارتفاعً في محتويات بيروكسيد بيد Nicotiana tabacum cv. Xanthi الهيدروجين في أوراق نبات التبغ المصاب بفيروس موزاييك التبخ عند درجات الحرارة العالية (30 مس) كما وحدثت زيادة غير معنوية في بيروكسيد الهيدروجين في أوراق النباتات المصابة بالفيروس عند حرارة 20 ْس بالمقارنة مع نباتات

\section{Abstract}

Al-Ajouriyeh, H., I. Ismail, B. Samra and F. Sahyouni. 2021. Effect of Cucumber Mosaic Virus on Proline and Hydrogen Peroxide Content in Some Pepper Hybrids Grown in Lattakia Governorate, Syria. Arab Journal of Plant Protection, 39(1): 39-46.

A study was conducted at Al-Muturki village in Lattakia Governorate during 2019/2020 growing season to investigate the effect Cucumber mosaic virus (CMV) infection on the proline and hydrogen peroxide $\left(\mathrm{H}_{2} \mathrm{O}_{2}\right)$ content of four pepper hybrids (Taline F1, Amani F1, Harek F1 and Marvilo F1) at three periods post viral inoculation (15, 30 and 45 days). The experiment was carried out by using complete randomized block design with 8 treatments and 8 replicates per treatment. The results showed that the viral infection affected the proline and hydrogen peroxidase content 15 days after virus inoculation. The highest effect of the viral infection was at 30 days after virus inoculation, where the values of proline and hydrogen peroxidase of the infected pepper hybrids significantly increased compared to control plants. However, 45 days after virus inoculation, the effect of viral infection decreased with plant age.

Keywords: Pepper, Cucumber mosaic virus, proline, hydrogen peroxidase.

Affiliation of authors: Hala Al-Ajouriyeh ${ }^{1}$, Imad Ismail ${ }^{1}$, Badih Samra ${ }^{2}$ and Fahed Sahyouni ${ }^{3}$. (1) Plant Protection Department, Faculty of Agriculture, Tishreen University, Lattakia, Syria, Email: hlaalajouria1986@gmail.com; (2) Horticulture Department, Faculty of Agriculture, Tishreen University, Lattakia, Syria; (3) Faculty of Agriculture 2, University of Aleppo, Deir Al-Zor, Syria. 
lycopersicum cv. Superchief) plants under biotic stresses. Iranian Journal of Plant Physiology, 8: 23452351.

https://doi.org/10.22034/IJPP.2018.539110

Govindarajan, V.S. and U.J. Salzer. 1985. Capsicumproduction, technology, chemistry, and quality part 1: History, botany, cultivation, and primary processing. Food Science and Nutrition, 22: 109-176. https://doi.org/10.1080/10408398509527412.

Kiraly, L., T.Y.M. Hafez, T.J. Fodor and Z. Kiraly. 2008. Suppression of tobacco mosaic virus-induced hypersensitive-type necrotization in tobacco at high temperature is associated with downregulation of NADPH oxidase and superoxide and stimulation of dehydroascorbate reductase. Journal of General Virology, 89: 799-808. https://doi.org/10.1099/vir.0.83328-0

Kiraly, Z., B. Barna, A. Kecskes and J. Fodor. 2002. Down-regulation of antioxidative capacity in a transgenic tobacco which fails to develop acquired resistance to necrotization caused by TMV. Free Radicals Research, 36: 981-991. https://doi.org/10.1080/1071576021000006581.

Love, A.J., B.W. Yun, V. Laval, G.J. Loake and J.J. Milner. 2005. Cauliflower mosaic virus, a compatible pathogen of Arabidopsis, engages three distinct defense-signaling pathways and activates rapid systemic generation of reactive oxygen species. Plant Physiology, 139: 935-948. https://doi.org/10.1104/pp.105.066803.

Lutts, S., V. Majerus and J. Kinet. 1996. NaCl-induced senescence in leaves of rice (Oryza sativa L.) cultivars different in salinity resistance. Annals of Botany, 78: 389-398. https://doi.org/10.1006/anbo.1996.0134

Madhusudhan, K.N., B.M. Srikanta, M.D. Shylaja, H.S. Prakash and H.S. Shetty. 2009. Changes in antioxidant enzymes, hydrogen peroxide, salicylic acid and oxidative stress incompatible and incompatible host-tobamovirus interaction. Journal of Plant Interactions, 4: 157-166.

https://doi.org/10.1080/17429140802419:516

Mansour, M.M.F. 2000. Nitrogen containing compounds and adaptation of plants to salinity stress. Biology Plantarum, 43: 491-500. https://doi.org/10.1023/A:1002873531707.

Mazid, M., T.A. Khan and F. Mohammad. 2011. Role of secondary metabolites in defense mechanisms of plants. Biology and Medicine 3: 232-249.

Montalbini, P., R. Buonaurio and N.N. Umesh Kumar. 1995. Peroxidase activity and isoperoxidase pattern in tobacco leaves infected with tobacco necrosis virus and other viruses inducing necrotic and non-necrotic alterations. Journal of Phytopathology, 143: 295-301. https://doi.org/10.1111/j.1439-0434.1995.tb00263.x

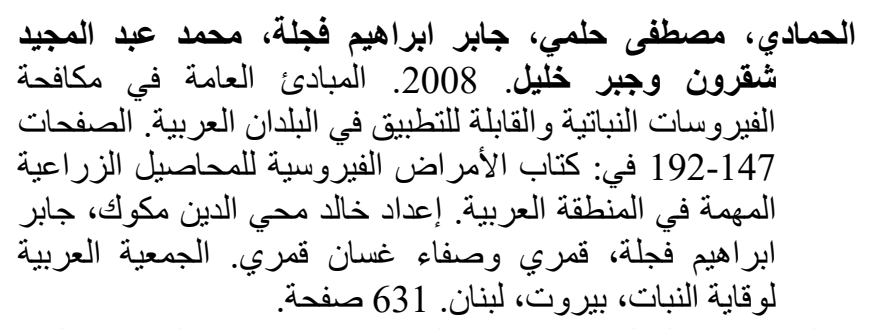

[El-Hamadi, M.H., G.I. Figla, M.A.M, Shakroun and J. Khalil. 2008. General principles for the control of plant viruses applicable to the Arab countries. Pages 147-192. In: Viral Diseases of Important Agricultural Crops in the Arab Region. K.M. Makkouk, G.I. Figla and S.G. Kumari (eds.). Arab Society for Plant Protection, Beirut, Lebanon. 631 pp. (In Arabic).]

العجوريه، حلا. 2015. تأثير موعد العدوى بفيروس موزاييك الخيار

على نباتات الفليفلة في الزراعات الحقلية في محافظة اللاذفية.

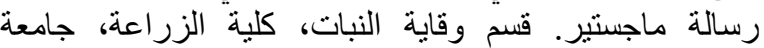

$$
\text { تشرين، اللاذقية، سورية. } 77 \text { صفحة. }
$$

[Al-Ajouriya, H. 2015. Effect of infection date with Cucumber mosaic virus on pepper plants in the open field in Lattakia Governorate. M.Sc. Thesis, Plant Protection Department, Faculty of Agriculture, Tishreen University, Lattakia, Syria. 77 pp. (In Arabic).]

وزارة الزراعة والإصلاح الزراعي. 2017. قسم الإحصاء، مديرية الإحصاء و التخطيط، دمشق، الإصلاع، سورية.

[Ministry and Agriculture and Land Reclamation. 2017. Statistics Department, Directorate of Statistics and Planning, Damascus, Syria. (In Arabic).]

Barakat, A. and Z.A. Torky. 2017. Molecular detection of Bean yellow mosaic virus in Lupinus albus plants and its associated alterations in biochemical and physiological parameters. Journal of Antivirals and Antiretrovirals, 9: 33-42.

https://doi.org/10.4172/1948-5964.1000159

Barnett, N.M. and A.N. Naylor. 1966. Amino acids and protein metabolism in Bermuda grass during water stress. Plant Physiology, 41: 1222-1230. https://doi.org/10.1104/PP.41.7.12222

Bates, L.S., R.P. Waldren and I.D. Tear. 1973. Rapid determination of free proline for water stress studies. Plant Soil, 39: 205-207. https://doi.org/10.1007/BF00018060

Berber, I. and H. Önlü. 2012. The levels of nitrite and nitrate, proline and protein profiles in tomato plants infected with Pseudomonas syringae. Pakistan Journal of Botany, 44: 1521-1526.

Doke, N. and Y. Ohashi. 1988. Involvement of an $0_{2}$ generating system in the induction of necrotic lesions on tobacco leaves infected with tobacco mosaic virus. Physiological and Molecular Plant Pathology, 32: 163-175. https://doi.org/10.1016/S0885-5765(88)80013-4

Gholi-Tolouie, S., M. Davari, N. Sokhandan-Bashir and M. Sedghi. 2018. Influence of salicylic and jasmonic acids on the antioxidant systems of tomato (Solanum 
Riedle-Bauer, M. 2000. Role of reactive oxygen species and antioxidant enzymes in systemic virus infections of plants. Journal of Phytopathology, 148: 297-302. https://doi.org/10.1046/j.1439-0434.2000.00503.x.

Shahrukh, I., Um. E. Aiman, S. Khan, N. Parveen, M. Fatima and M. Umar Dahot. 2014. Certain growthrelated attributes of bunchy top virus infected banana under ex-vitro conditions. African Journal of Biotechnology, 13: 1876-1882. https://doi.org/10.5897/AJB11.2093

Soleimani, P., G. Mosahebi and M.K. Habibi. 2011. Identification of some viruses causing mosaic on lettuce and characterization of Lettuce mosaic virus from Tehran Province in Iran. African Journal of Agricultural Research, 6: 3029-3035. https://doi.org/10.5897/AJAR11.114

Stewart, G.R. 1983. Proline accumulation: Biochemistry aspects. Pages 243-259. In: Physiology and Biochemistry of Drought Resistance in Plants. L.G. Paleg and D. Aspinall (eds.). Academic Press, Australia. 492 pp.

Velikova, V., I. Yordanov and A. Edreva. 2000. Oxidative stress and some antioxidant systems in acid rain-treated bean plants: Protective role of exogenous polyamines. Plant Science, 151:59-66. https://doi.org/10.1016/S0168-9452(99)00197-1

Xi, D., H. Feng, L. Lan, J. Du, J. Wang, Z. Zhang, L. Xue, W. Xu and H. Li. 2007. Characterization of synergy between Cucumber mosaic virus and Tobacco necrosis virus in Nicotiana benthamiana. Journal of Phytopathology, 155: 570-573. https://doi.org/10.1111/j.1439-0434. 2007.01279.x

Zehnder, G.W., J.F. Murphy, E.J. Sikora and J.W. Kloepper. 2001. Application of rhizobacteria for induced resistance. European Journal of Plant Pathology, 107: 39-50. https://doi.org/10.1023/A:1008732400383

Received: September 10, 2020; Accepted: January 3, 2021
Neuenschwander, U., B. Vernooij, L. Friedrich, S. Uknes, H. Kessmann and J. Ryals. 1995. Is hydrogen peroxide a second messenger of salicylic acid in systemic acquired resistance? Plant Journal, 8: 227-233.

https://doi.org/10.1046/j.1365-313x.1995.08020227.x

Palfi, G. and J. Juhasz. 1969. Relationships among water deficiency, salinity of cold root medium and proline, pipecolic acid and total amino acid content of plants. Zeitschrift fur Pflanzenernaehrungund Bodenkunde, 124: $36-128$. https://doi.org/10.1007/BF02878408.

Pazarlar, S., M. Gümüş and G. Öztekin. 2013. The effects of Tobacco mosaic virus infection on growth and physiological parameters in some pepper varieties (Capsicum annuum L.). Notulae Botanicae Horti Agrobotanici Cluj-Napoca, 41: 427-433. https://doi.org/10.15835/nbha4129008.

Petrova, D., G. CHaneva, E. Stoimenova and V. Kapchina-Toteva. 2012. Effect of Cucumber Mosaic virus on the Contents of Chlorophyll, Proline, the Degree of Lipid Peroxidation and Phenotypic Expression of Pepper Lines with Different Susceptibility to Virus. Oxidation Communications, 35: 182-189.

Radwan, D.E.M., K.A. Fayez, S.Y. Mahmoud, A. Hamad and G. Lu. 2007. Physiological and metabolic changes of Cucurbita pepo leaves in response to Zucchini yellow mosaic virus (ZYMV) infection and salicylic acid treatments. Plant Physiology and Biochemistry, 45:480-489. https://doi.org/10.1016/j.plaphy.2007.03.002.

Rayapati, P.J. and C.R. Stewart. 1991. Solubilization of protin dehydrogenase from maize (Zea mays L.) mitochondria. Plant Physiology, 95: 787-791. https://doi.org/10.1104/PP.95.3.787.

تاريخ الاستلام: 2020/9/10؛ تاريخ الموافقة على النشر: 2021/1/3 